\title{
Frequency of Inflammatory Cell Types in Polyps of Patients with Diffuse Sinonasal Polyposis and Association with Effective Factors in Recurrence
}

\author{
Ali Reza Lotfi ${ }^{1}$, Nikzad Shahidi ${ }^{1}$, Monireh Halimi ${ }^{2}$ and Seyedeh Nafisseh Es-Hagh Hosseini ${ }^{1, *}$ \\ ${ }^{1}$ Department of Otorhinolaryngology-Head and Neck Surgery, Tabriz University of Medical Sciences, Tabriz, Iran \\ 2 Department of Pathology, Tabriz University of Medical Sciences, Tabriz, Iran \\ * Corresponding author: Seyedeh Nafisseh Es-Hagh Hosseini, Department of Otorhinolaryngology-Head and Neck Surgery, Tabriz \\ University of Medical Sciences, Tabriz, Iran. Tel: 09022038838; Email: eshagh.hosseini@gmail.com
}

Received 2020 0ctober 01; Revised 2020 0ctober 19; Accepted 2020 0ctober 27.

\begin{abstract}
Background: Sinonasal polyposis (SNP) is a chronic disease of nasal and paranasal sinus mucosa. Nasal polyps can be divided into two groups based on inflammatory cells' types, namely eosinophilic and neutrophilic polyps. Eosinophilic chronic rhinosinusitis responds to corticosteroids; however, this response is less in the neutrophilic type.

Objectives: The present study aimed to determine the frequency of inflammatory cell types in the polyp tissue of patients with diffuse SNP and its association with effective factors in recurrence.

Methods: This cross-sectional study was carried out on 130 patients with diffuse SNP referring to the Ear, Nose, and Throat (ENT) clinics of Tabriz University of Medical Sciences, Tabriz, Iran in 2017, using random sampling. The severity of the disease was assessed by the Sinonasal Outcome Test 20 (SNOT-20) questionnaire filled out by an ENT surgeon. Computed tomography scans were graded by the Lund-Mackay score. The variety of the cells were determined following hematoxylin-eosin staining and pathologist light microscopy examination; then, the obtained data were statistically evaluated and their associations with the previously known factors of recurrence in other studies were reported.

Results: The most frequent cells were eosinophils, and mast cells showed the lowest frequency of inflammatory cells in the polyps of patients with diffuse SNP. Eosinophilic polyps were more common in female patients. There was no significant difference between inflammatory cells associated with age, history of surgery, and SNOT-20 score. A significant relationship was only observed between the Lund-Mackay scores of neutrophil and mast cell counts in polyps.

Conclusion: The investigation of the dominant inflammatory cell in the histopathology sample of the sinonasal polyps can help in tracking and rationalizing patient management and expectations.
\end{abstract}

Keywords: Lund-Mackay score, Recurrence, Sinonasal polyposis, SNOT-20

\section{Background}

Sinonasal polyposis (SNP) is a chronic disease of nasal and paranasal sinus mucosa that is hyperplasia and protrusion of sinus mucosa secondary to chronic inflammation. The most common sites of involvement are the ethmoidal cells $(1,2)$. In histopathology, SNP is identified by epithelial proliferation, glandular hyperplasia, and thickening of basal membrane, edema, and fibrosis, and infiltration of inflammatory cells, especially eosinophils, neutrophils, mast cells, lymphocytes, plasma cells, and macrophages $(3,4)$.

Polyps are in fact stromal edema and infiltration of inflammatory cells (5). The prevalence of this disease is estimated within $1-4 \%$ of the normal population. Nasal polyps can be divided into two groups based on inflammatory cells' types, namely eosinophilic and neutrophilic polyps, and the eosinophilic type is considered the most common type $(5,6)$. No etiologic factor has been proven for SNP; however, environmental factors are more proposed in this regard (7). Some theories suggest that the factors leading to chronic inflammation have an effect on polyp formation. Many researchers are looking for independent risk factors of SNP (8). Neutrophil/lymphocyte and platelet/lymphocyte ratios in peripheral blood smear are suggested as inflammatory markers (9).

Historically, nasal polyposis and sinuses were determined as eosinophilic polyposis due to allergic causes and totally related to the immune system. However, recent investigations have shown that in some cases nasal polyposis and sinuses in chronic sinus are due to mucosa stimulation with pathogen factors; therefore, these patients have no allergic symptoms. According to the most recent view, the role of fungi has been proposed in nasal polyposis and sinuses; nevertheless, this has not yet been proven.

In the histopathologic study, most polyps are secondary to eosinophilic chronic rhinosinusitis (ECRS) in western countries. In addition, $80 \%$ of polyposis in western countries is accompanied by severe T helper 2 response, eosinophilic infiltration, T-cell regulation decrease, and interleukin-5 increase. This pattern is different from those of China and other Asian countries, such as Korea and Thailand, which is compatible with T helper 1 and $\mathrm{T}$ helper 17 inflammatory patterns as a second inflammatory pattern $(10,11)$. The ECRS responds to corticosteroids; however, this response is less in the neutrophilic type (12). Lou et al. divided SNP 
into five groups, including 1) dominant plasma cells, 2) lymphocytes, 3) neutrophils, 4) eosinophils, and 5) mixed inflammatory cells. The results of the aforementioned study demonstrated different recurrences in these five groups (13).

The primary goal of the treatment of polyps is to achieve and maintain clinical control. Different treatment options are available for SNP. Local corticosteroids have shown beneficial effects, compared to placebo, and become part of the standard treatment. Oral corticosteroids are sometimes prescribed with antibiotics or topical corticosteroids; however, there is no evidence to prescribe them as a single treatment, and side effects should be considered. The broad spectrum of shortterm antibiotics is used only in cases of acute exacerbations. Long-term macrolides may also have anti-inflammatory effects, which was shown by two clinical trials. Saline solutions are often used as adjuvant therapies for other treatments. Saline solutions reduce the symptoms if they are used alone, which has been proven in meta-analyses (14). Antiimmunoglobulin E (IgE) antibodies have also been used for the treatment of SNP (15).

Surgery is one of the auxiliary treatments for the removal of complications of the disease and opening of the nasal passages (16); nevertheless, the relapse of nasal polyps after treatment is very problematic, and the rate of post-surgical relapse, especially in the widespread cases of the disease, remains very high (17). The need for re-surgery in SNP patients is estimated at about 10\% (18).

Sinus surgery is considered for patients not recovering through the medicine after the maximum treatment of polyps, reduces nasal symptoms, and improves the quality of life of patients (19). Reducing the size of polyps in surgical treatment is much more than medical treatment. Even in parallel treatment with anti-inflammatory drugs, there is a possibility of the recurrence of the disease after 5 to 10 years. On the other hand, with all the accepted treatments, a group of patients with recurrent disease, asthma, and inflammation are known as T helper 2 inflammatory patients which are resistant to treatment $(20,21)$.

To date, there has been no report on the predictive markers of postoperative recurrence that can be identified before surgery. If the relative risk of recurrence can be theoretically determined before surgery, it can greatly contribute to the identification of patients at higher risk of recurrence; accordingly, they are more likely to suffer from the disease (or they become more aware of the disease) and are more closely monitored.

Many researchers are looking for independent risk factors for the recurrence of the disease in SNP patients. The extensive disease in computed tomography (CT) scans, history of surgery, peripheral eosinophilia, mucosal eosinophilia, asthma, and frontal sinus involvement are the risk factors reported in previous studies and are related to increased postoperative relapse. However, some studies have suggested that there is no association between SNP recurrence after surgery with the degree of involvement in the CT scan, IgE levels, comorbid allergic rhinitis, and fungal presence $(21,22)$.

Another study was conducted on 40 patients with SNP in Turkey in 2014. In the aforementioned study, the patients were divided into two groups, namely predominant eosinophilic and predominant neutrophilic. According to the results of the aforementioned study, there was no significant difference between the 6-month follow-up of patients regarding relapse (23).

A prospective study was carried out in one of the centers of Isfahan University of Medical Sciences, Isfahan, Iran, for the examination of 30 patients with nasal polyposis undergoing endoscopic nasal and sinus surgery within April 2004 and November 2006. In the aforementioned study, after careful examination and completion of related history, the patients underwent surgery, and the samples were sent to a laboratory for pathological examination. Based on the pathological criteria, the polyps were divided into two groups of eosinophilic and neutrophilic. Then, an analytical study was conducted to investigate the relationship between the findings of the aforementioned study and criteria derived from historical and physical examinations. Accordingly, it was concluded that eosinophilic polyposis is the most common type of nasal polyposis, and the frequency of polyposis in men is higher than reported for women. In addition, allergic diseases and nasal anatomy disorders are the most important factors associated with nasal polyposis (24).

\section{Objectives}

However, given the above-mentioned considerations, effective factors in nasal polyposis, prevalence of allergies in the context of polyps, climatic differences in SNP histology in the world associated with the predictive factors of relapse and response to treatment in previous studies, and absence of a study in this regard in the northwest of Iran, the present study aimed to investigate the histopathology of the inflammatory cells of sinonasal polyps to identify the factors associated with better response to treatment and justify the severity of the symptoms and likelihood of a lower recurrence after surgery; accordingly, more information can be provided for physicians to treat such patients.

\section{Methods}

This cross-sectional study was carried out on patients with diffuse SNP referring to the Ear, Nose, and Throat (ENT) clinics of educational hospitals of Tabriz University of Medical Sciences, Tabriz, Iran in 
2017. The data of this study were collected using simple random sampling. Cohen's formula was used in this study for the calculation of the sample size (25). The inclusion criteria of the study were patients with diffuse SNP undergoing surgical treatment and presence of sinonasal tissue. The study subjects were within the age range of 15-45 years. The exclusion criteria were as follows:

1) History of antibiotic use (including the full range of systemic antibiotics) within 2 weeks prior to sinus surgery

2) History of steroid use (oral or intravenous) within 2 weeks prior to sinus surgery

3) History of constipation drugs during 2 weeks prior to sinus surgery

4) Diagnosis of diabetes under treatment

5) Immune deficiencies (i.e., congenital or acquired immunodeficiency or treatment-induced immunodeficiency)

6) Kidney diseases (i.e., acute or chronic with a glomerular filtration rate of less than $60 \mathrm{~mL} / \mathrm{min}$ )

7) Liver diseases (i.e., parenchymal liver disease or tract with an enzyme disorder more than twice the normal level)

8) Vasculitis (i.e., systemic and cutaneous)

\subsection{Steps of the research process}

Firstly, the research objectives were explained to the patients meeting the inclusion criteria, and then informed consent was obtained to enter the study. Afterward, the severity of the disease based on the symptoms was measured by the Sinonasal Outcome Test 20 (SNOT-20) forms and researcher's questions. The use of a valid scale is required for the evaluation of the disease and effects of the treatment. In multiple studies, including studies conducted in Iran, the SNOT-20 has been used as the outcome criterion. This test is a valid scale for the assessment of the quality of life and health of the nose and sinuses $(26,27)$.

The SNOT-20 is a 20 multi-choice and selfcontained item test, usually scanned with a score summary (0 to 5) without a sub-score card $(28,29)$. In this questionnaire, patients describe their health status according to the severity of symptoms and their quality of life by indicating the importance of different domains, including physical problems, functional constraints, and emotional consequences of surgery $(29,30)$. In the SNOT-20, the average score of 20 items is calculated, and patients are asked to identify the items that are most important to them. German, Chinese, Portuguese, Japanese, and Persian versions are available for the SNOT-20. The validity and reliability of the Persian version were confirmed by Naghdi et al.; accordingly, the coefficients of SNOT20 Cronbach's alpha were calculated at 0.88 and 0.9 for the test and re-test, respectively (31). On the other hand, the patient CT scan is evaluated in terms of the severity of the disease by the Lund-Mackay

\begin{tabular}{lcc}
\hline Table 1. Lund-Mackay staging system & & \\
\hline Sinus system & Left & Right \\
\hline Maxillary & $0-2$ & $0-2$ \\
Anterior ethmoidal & $0-2$ & $0-2$ \\
Posterior ethmoidal & $0-2$ & $0-2$ \\
Sphenoidal & $0-2$ & $0-2$ \\
Frontal & $0-2$ & $0-2$ \\
Ostiomeatal complex & 0 or 2 & 0 or 2 \\
Total points for each side & $0-24$ & $0-24$ \\
\hline *Soring for all
\end{tabular}

*Scoring for all sinus systems: 0=No abnormalities;1=Partial opacification; $2=$ Total opacification

For the ostiomeatal complex: $0=$ Not occluded; $2=0$ ccluded

score which is shown in Table 1 (32). Firstly, the clinical data of the samples, including age and gender, were recorded in tables. Then, a 5-micron incision for hematoxylin-eosin staining was performed to confirm the diagnostic histopathology of the paraffin blocks. After being observed by a pathologist and confirming the diagnosis, the number of inflammatory cells of any type was determined according to the Tasi method. In the samples taken from the polyp tissue of the patients undergoing surgery, firstly the number of hematoxylin-eosin stained inflammatory cells were counted with a magnification of x40 in 100 highpower fields under light microscopy (33-35), and the average number of cells was reported. In addition, the numerical densities of eosinophils, neutrophils, mast cells, lymphocytes, plasma cells, and macrophages were also calculated (36).

\section{Results}

The current study was performed on 130 samples of the patients with diffuse SNP referring to the ENT clinics of Tabriz University of Medical Sciences teaching hospitals. According to the obtained data in this study, most male participants (64\%) were under diploma $(60 \%)$ and within the age range of $26-35$ years $(30 \%)$. In addition, $15 \%, 16 \%$, and $27 \%$ of the participants in the study had a history of polyp surgery, cigarette smoking, and asthma, respectively. According to other results of this study, the frequency rates of inflammatory cell types in the polyp tissue of patients with diffuse SNP were reported as $57 \%$, $28 \%, 11 \%, 2 \%$, and $4 \%$ for eosinophils, neutrophils, lymphocytes, plasmas, and mast cells, respectively. Table 2 shows the frequency of the types of inflammatory cells in the polyps of patients with diffuse SNP. According to the results shown in Table 2 , only the frequency of eosinophils was different

Table 2. Frequency of types of inflammatory cells in polyps of patients with sinonasal diffuse polyposis

\begin{tabular}{lccc}
\hline $\begin{array}{l}\text { Inflammatory cell } \\
\text { type }\end{array}$ & $\begin{array}{c}\text { Female } \\
\text { (\%) }\end{array}$ & $\begin{array}{c}\text { Male } \\
\text { (\%) }\end{array}$ & P-value \\
\hline Eosinophils & 62 & 52 & 0.041 \\
Neutrophils & 24 & 28 & 0.346 \\
Lymphocytes & 8 & 13 & 0.101 \\
Plasma cells & 2 & 3 & 0.055 \\
Mast cells & 4 & 4 & 0.496 \\
\hline
\end{tabular}


Table 3. Frequency of types of inflammatory cells based on age in polyposis in patients with diffuse sinonasal polyposis

\begin{tabular}{lcccccc}
\hline Inflammatory cell type & Under 25 years & 26-35 years & $\mathbf{3 6 - 4 5}$ years & 46-55 years & Over 65 years & P-value \\
\hline Eosinophils (\%) & 60 & 59 & 60 & 49 & 48 & 0.414 \\
Neutrophils (\%) & 26 & 24 & 25 & 35 & 29 & 0.144 \\
Lymphocytes (\%) & 9 & 11 & 10 & 11 & 16 & 0.544 \\
Plasma cells (\%) & 2 & 1 & 2 & 2 & 3 & 0.432 \\
Mast cells (\%) & 3 & 5 & 3 & 3 & 4 & 0.119 \\
\hline
\end{tabular}

Table 4. Frequency of inflammatory cell types based on history of surgery of polyposis in polyps of patients with diffuse sinonasal polyposis

\begin{tabular}{lccc}
\hline Inflammatory cell type & Not related & related & P-value \\
\hline Eosinophils (\%) & 56 & 56 & 0.993 \\
Neutrophils (\%) & 31 & 27 & 0.332 \\
Lymphocytes (\%) & 7 & 12 & 0.176 \\
Plasma cells (\%) & 2 & 2 & 0.90 \\
Mast cells (\%) & 4 & 4 & 0.625 \\
\hline
\end{tabular}

between the two genders.

According to the results shown in Table 3, only the eosinophil percentage was different between males and females.
According to the results presented in Table 4, there were no significant differences regarding the analyzed data.

According to the results reported in Table 5, a history of surgery did not have a significant relationship with the inflammatory cells of the polyp sample; however, a history of cigarette smoking and asthma was significantly associated with the rates of mast cells and lymphocytes, respectively

According to the results shown in Table 6, the most frequently involved areas in the paranasal sinuses were the ostiomeatal complex and frontal sinus, respectively.

Table 5. Relationship between history of smoking, polyp surgery, and asthma with prevalence of diffuse sinonasal polyposis in patients referring to Tabriz University of Medical Sciences, Tabriz, Iran, in 2017

\begin{tabular}{lccccccccc}
\hline \multirow{2}{*}{ Inflammatory cell type } & \multicolumn{3}{c}{ History of asthma } & \multicolumn{3}{c}{ History of smoking } & \multicolumn{3}{c}{ History of polyp surgery } \\
\cline { 2 - 10 } & P-value & Yes (\%) & No (\%) & P-value & Yes (\%) & No (\%) & P-value & Yes (\%) & No (\%) \\
\hline Eosinophils & 0.121 & 61 & 53 & 0.584 & 51 & 55 & 0.993 & 56 & 56 \\
Neutrophils & 0.965 & 28 & 28 & 0.564 & 27 & 30 & 0.332 & 31 & 27 \\
Lymphocytes & 0.014 & 8 & 13 & 0.171 & 15 & 10 & 0.176 & 7 & 12 \\
Plasma cells & 0.912 & 2 & 2 & 0.065 & 3 & 2 & 0.900 & 2 & 2 \\
Mast cells & 0.220 & 4 & 3 & 0.022 & 5 & 4 & 0.625 & 4 & 4 \\
\hline
\end{tabular}

Table 6. Frequency and percentage of pathologic sites of patients with diffuse sinonasal polyposis referring to Tabriz University of Medical Sciences, Tabriz, Iran, based on Lund-Mackay staging system

\begin{tabular}{lcccccc}
\hline \multirow{2}{*}{ Score } & $\mathbf{n}$ & $\mathbf{0}$ & & $\mathbf{1}$ & & $\mathbf{2}$ \\
\cline { 2 - 8 } & $\mathbf{n}$ & $\mathbf{0}$ & $\mathbf{n}$ & $\mathbf{\%}$ & $\mathbf{n}$ & $\mathbf{\%}$ \\
\hline Ostiomeatal complex & 33 & 24 & - & - & 97 & 76 \\
Frontal & 25 & 20 & 7 & 5 & 96 & 75 \\
Sphenoidal & 29 & 23 & 8 & 6 & 92 & 71 \\
Posterior ethmoidal & 49 & 39 & 12 & 9 & 66 & 52 \\
Anterior ethmoidal & 38 & 29 & 5 & 4 & 86 & 67 \\
\hline
\end{tabular}

According to the results presented in Table 7, the need to blow nose was the most frequently observed symptom among the patients.

According to the results reported in Table 8, the SNOT-20 score had a significant correlation with the inflammatory cell type. The Lund-Mackay score significantly correlated with mast cell and then neutrophil and eosinophil inflammatory cell types, respectively.

Table 7. Prevalence of problems of patients with diffuse sinonasal polyposis referring to Tabriz University of Medical Sciences, Tabriz, Iran, in 2017 according to the results of Sinonasal Outcome Test 20

\begin{tabular}{lcc}
\hline Symptom & n & \% \\
\hline Need to blow nose & 75 & 57 \\
Sneezing & 43 & 32 \\
\hline
\end{tabular}

\begin{tabular}{lcc}
\hline Table 7. Continued & & \\
\hline Runny nose & 59 & 44 \\
Cough & 28 & 21 \\
Post-nasal discharge & 62 & 47 \\
Thick nasal discharge & 59 & 44 \\
Ear fullness & 31 & 23 \\
Dizziness & 13 & 10 \\
Ear pain & 10 & 8 \\
Facial pain/pressure & 28 & 21 \\
Difficulty falling asleep & 51 & 38 \\
Wake up at night & 58 & 44 \\
Lack of a good night sleep & 57 & 43 \\
Wake up tired & 57 & 43 \\
Fatigue & 52 & 39 \\
Reduced productivity & 46 & 35 \\
Reduced concentration & 41 & 31 \\
Frustration/Restlessness/Irritability & 45 & 34 \\
Sadness & 35 & 26 \\
Embarrassment & 30 & 22 \\
\hline
\end{tabular}


Table 8. Relationship between Sinonasal Outcome Test 20 score and Lund-Mackay score with prevalence of diffuse sinonasal polyposis among patients referring to Tabriz University of Medical Sciences, Tabriz, Iran, in 2017

\begin{tabular}{|c|c|c|c|c|}
\hline \multirow{2}{*}{ Inflammatory cell type } & \multicolumn{2}{|c|}{ Lund-Mackay score } & \multicolumn{2}{|c|}{ SNOT-20 score } \\
\hline & P-value & Correlation & P-value & Correlation \\
\hline Eosinophils & 0.028 & 0.237 & 0.991 & -0.001 \\
\hline Neutrophils & 0.017 & -0.256 & 0.864 & 0.019 \\
\hline Lymphocytes & 0.686 & -0.045 & 0.840 & -0.022 \\
\hline Plasma cells & 0.608 & -0.058 & 0.592 & -0.060 \\
\hline Mast cells & 0.009 & -0.286 & 0.833 & -0.024 \\
\hline
\end{tabular}

SNOT-20: Sinonasal Outcome Test 20

\section{Discussion}

The SNP is a chronic disease of the nasal mucosa and paranasal sinuses secondary to chronic inflammation. Nasal aberration is a common anatomical disorder that can contribute to the chronic inflammation of the sinuses and nasal polyposis (36). Given that the predictive markers for postoperative recurrence, which can be detected before surgery, have not been reported to date, if the relative risk of recurrence before surgery can be theoretically determined, it can greatly contribute to the identification of patients at higher risk of recurrence; accordingly, they become more aware of the course of the disease and more accurately tracked. Many researchers are looking for risk factors associated with the recurrence of disease in SNP patients. In this regard, the extensive disease in CT scans, history of previous surgery, peripheral eosinophilia, mucosal eosinophilia, asthma, and frontal sinus involvement are the risk factors mentioned in previous studies related to increased postoperative relapse.

However, some studies have suggested that there is no association between SNP recurrence after surgery with the degree of involvement in CT scan, IgE levels, and co-infection with allergic rhinitis, and fungal presence (24-28). Therefore, the present study was performed on 130 samples of the patients with diffuse SNP referring to the ENT clinics of Tabriz University of Medical Sciences teaching hospitals. The obtained results showed that the prevalence of this disorder was higher in male patients and subjects within the age range of 26-35 years.

The obtained results of the present study demonstrated that eosinophils $(n=56)$, neutrophils $(n=28)$, lymphocytes $(n=11)$, and plasma and mast cells $(n=6)$ were reported with the highest to the lowest frequency of the inflammatory cells in the polyp tissue of patients with diffuse SNP, respectively. The eosinophilic type rhinosinusitis is associated with corticosteroid response; however, neutrophilic type patients are less responsive to corticosteroids $(36,37)$. In this regard, the results of this study are slightly different from the findings of a study carried out by Luo et al. In the aforementioned study, it was shown that the prevalence of plasmas, lymphocytes, neutrophils, eosinophils, and mixed inflammatory cells are different in recurrence rates
(13). In another study conducted on 40 patients with SNP in Turkey in 2014, the participants were divided into two groups, namely eosinophil dominant and neutrophil dominant. According to the results, a significant difference was observed in the 6-month follow-up of recurrence (23).

In the histological examination of the polyp tissue of patients with diffuse SNP, the majority of polyps among the participants of Western countries were secondary to inflammation resulting from ECRS (38). In addition, $80 \%$ of polyposis in the Western countries is accompanied by a severe $\mathrm{T}$ helper 2 response, eosinophilic infiltration, decreased T-cell regulator function, and increased interleukin-5. This pattern is contrary to the patterns observed in China and other Asian countries, such as Thailand and Korea, which are consistent with the inflammatory patterns of T helper 1 and T helper 17 (38). This type II shows the type II inflammation pattern (39).

The obtained results of the current study revealed that the prevalence of eosinophils in men was $11 \%$ higher than that reported for women. However, this difference was not significant for other inflammatory cells (i.e., neutrophils, lymphocytes, plasma cells, and mast cells). In this regard, the findings of the current study are consistent with the results of a study by Baluchi et al. In a prospective study, it was shown that eosinophilic polyposis is the most common type of nasal polyposis, and the frequency of polyposis is higher among men than that of women. In addition, allergic diseases and nasal congestion are the most important factors associated with nasal polyposis (24).

The results of this study showed no significant difference between age and history of surgery with the prevalence of inflammatory cell types. Previous studies have demonstrated that a history of surgery, peripheral eosinophilia, mucosal eosinophilia, asthma, triad control, and frontal sinus involvement are considered the risk factors associated with increased postoperative relapse. However, some studies have suggested that there is no relationship between SNP recurrence after surgery with the degree of involvement in CT scan, IgE levels, coinfection with allergic rhinitis, and presence of fungi (21-25).

The final results of the SNOT-20 in this study showed that the need to blow nose, posterior nasal discharge, rhinorrhea, nasal congestion, waking up at 
night, lack of comfortable night sleep, and tired waking were respectively the most common problems of the patients with diffuse SNP referring to the educational and therapeutic clinics of Tabriz University of Medical Sciences during 2017. Therefore, the results of the present study are consistent with the findings of previous studies.

On the other hand, no significant relationship was observed between the SNOT-20 scores and various types of inflammatory cells, which may indicate that the polyp cell type does not affect the patient quality of life and polyposis plays an important role in the quality of life of the patients. According to the results of the Lund-Mackay scoring system, the most common conflict was reported in the ostiomeatal complex and the least involvement was reported in the posterior ethmoidal sinus.

Furthermore, there was a significant relationship between the Lund-Mackay score with the frequency of eosinophils, neutrophils, and mast cells in pathologic study. The highest correlation was observed between the frequency of mast cells and severity of the radiological involvement of the disease, after which the neutrophil and eosinophil levels had a significant correlation with the severity of the disease. On the other hand, there was no significant relationship between the Lund-Mackay score and frequency of lymphocytes and plasma cells.

Sinus surgery is considered in patients not medically recovering after a maximum treatment of polyps. Sinus surgery also reduces nasal symptoms and improves the quality of life of patients (19). Decreasing the size of polyps in the treatment by surgery is much more than that in medical treatment. Even if they are treated in parallel with anti-inflammatory drugs, there is a possibility of recurrence of the disease after 5 to 10 years (19, 20, 37).

The advantages of this study were a sufficient number of cases and operation/examination by a single researcher (i.e., an ENT surgeon). Using both the quality of life score (the SNOT-20) and radiologic score (the Lund-Mackay) helps to match subjective and objective data. The limitations of the current study were the cross-sectional nature of the study and inability for patient follow-up. On the other hand, sampling in only one province which restricts generalizing the results to the whole population was reported as another limitation of this study.

\section{Conclusion}

The presence of eosinophils, neutrophils, and especially mast cells, significantly was related to higher Lund-Mackay scores. There was no significant relationship between the type of inflammatory cells and demographic data or SNOT-20 score. Mast cells were significantly more prevalent among smokers. The investigation of the dominant inflammatory cells in histopathology samples of sinonasal polyps can help in tracking and rationalizing patient management and expectations.

\section{Acknowledgments}

The authors would like to express their gratitude to Dr. Zhila MohammadiAzar for her guidance and corporation. The authors would also like to show appreciation for the help of senior residents of ENT in data collection. They would like to express their gratitude to those who helped to finish this research project, particularly head nurses and nursing staff of the Imam Reza hospital in Tabriz, Iran.

\section{Footnotes}

Authors' Contribution: S.N. Es-Hagh Hosseini: Data collection, surgery, analysis, article writing

A. Lotfi: Chief surgeon and supervisor

N. Shahidi: Advisor

M. Halimi: Pathologist and advisor

Conflict of Interests: The authors declare that there is no conflict of interest.

Ethical Approval: The authors observed all the principles of the Declaration of Helsinki during the course of study. Personal information disclosure is avoided, and the results of the examinations were reported to the patients. Informed consent was obtained from all the subjects for participation in this research project.

Funding/Support: The current study was supported by Tabriz University of Medical Sciences without any financial support.

Informed consent: The informed consent form was designed according to the present study and read and signed by the patients before entering the study. In addition, the participants gave consent to participate in this study.

\section{References}

1. Erbek SS, Yurtcu E, Erbek S, Atac FB, Sahin FI, Cakmak O. Proinflammatory cytokine single nucleotide polymorphisms in nasal polyposis. Arch Otolaryngol Head Neck Surg. 2007; 133: 705-9. doi: 10.1001/archotol.133.7.705. [PubMed: 17638785].

2. Tasi CH, Weng SF, Rang LC, Huang YC, Huang FM, Chen YJ, et al. Immunohistochemical localization of tissue-type plasminogen activator inhibitor in radicular cysts. J Oral Patho Med. 2004;33(3):151-6. doi: 10.1111/j.0904-2512.2004.00133.x. [PubMed: 15128057].

3. Linder A, Karlsson-Parra A, Hirvela C, Jonsson L, Koling A, Sjoberg O. Immunocompetent cells in human nasal polyps and normal mucosa. Rhinology. 1993;31(3):125-9. [PubMed: 8256081].

4. Hirschberg A, Jókúti A, Darvas Z, Almay K, Répássy G, Falus A. The pathogenesis of nasal polyposis by immunoglobulin $\mathrm{E}$ and interleukin-5 is completed by transforming growth factorbeta1. Laryngoscope. 2003;113(1):120-4. doi: 10.1097/ 00005537-200301000-00022. [PubMed: 12514394].

5. Bikhazi NB. Contemporary management of nasal polyps. Otolaryngol Clin North Am. 2004;37(2):327-37. doi: 10.1016/ S0030-6665(03)00154-3. [PubMed: 15064065]. 
6. Riccio AM, Tosca MA, Cosentino C, Pallestrini E, Ameli F, Canonica GW et al. Cytokine pattern in allergic and non-allergic chronic rhinosinusitis in asthmatic children. Clin Exp Allergy. 2002;32(3):422-6. doi: 10.1046/j.1365-2222.2002.01315.x. [PubMed: 11940073].

7. Wynn R, Har-El G. Recurrence rates after endoscopic sinus surgery for massive sinus polyposis. Laryngoscope. 2004; 114(5):811-813. doi: 10.1097/00005537-200405000-00004. [PubMed: 15126735].

8. Bateman ND, Fahy C, Woolford TJ. Nasal polyps: still more questions than answers. J Laryngol Otol. 2003;117(1):1-9. doi: 10.1258/002221503321046577. [PubMed: 12590849].

9. Rot A, Krieger M, Brunner T, Bischoff SC, Schall TJ, Dahinden CA. RANTES and macrophage inflammatory protein 1 alpha induce the migration and activation of normal human eosinophil granulocytes. J Exp Med. 1992;176(6) 1489-95. doi: 10.1084/jem.176.6.1489. [PubMed: 1281207].

10. Ikeda K, Shiozawa A, Ono N, Kusunoki T, Hirotsu M, Homma H, et al. Subclassification of chronic rhinosinusitis with nasal polyp basedon eosinophil and neutrophil. Laryngoscope. 2013;123(11):E1-9.. doi: 10.1002/lary.24154. [PubMed: 23670893].

11. Chaaban MR, . Walsh EM, Woodworth BA. Epidemiology and differential diagnosis of nasal polyps. Am I Rhinol Allergy. 2013;27(6), 473-478. doi: 10.2500/ajra.2013.27.3981. [PubMed: 24274222].

12. Wen W, Liu W, Zhang L, Bai J, Fan Y, Xia W, et al. Increased neutrophilia in nasal polyps reduces the response to oral corticosteroid therapy. J Allergy Clin Immunol. 2012;129(6): 1522-8.e5. doi: 10.1016/j.jaci.2012.01.079. [PubMed: $22460066]$.

13. Lou H, Meng Y, Piao Y, Wang C, Zhang L, Bachert C. Predictive significance of tissue eosinophilia for nasal polyp recurrence in the Chinese population. Am J Rhinol Allergy. 2015;29(5):350-6. doi: 10.2500/ajra.2015.29.4231. [PubMed: 26219765].

14. Peters AT, Spector S, Hsu J, Hamilos DL, Baroody FM, Chandra RK, et al. Diagnosis and management of rhinosinusitis: a practice parameter update. Ann Allergy Asthma Immunol. 2014;113(4):347-85. doi: 10.1016/j.anai.2014.07.025. [PubMed: 25256029].

15. Bachert C, Zhang L, Gevaert P.Current and future treatment options for adult chronic rhinosinusitis: Focus on nasal polyposis. J Allergy Clin Immunol. 2015;136(6):1431-1440. doi: 10.1016/j.jaci.2015.10.010. [PubMed: 26654192].

16. Boztepe OF, Gün T, Demir M, Gür ÖE, Ozel D, Doğru H. A novel predictive marker for the recurrence of nasal polyposis following endoscopic sinus surgery. Eur Arch Otorhinolaryngol. 2015;273(6):1439-44. doi: 10.1007/s00405-015-3753-z. [PubMed: 26285781].

17. Tosun F, Arslan HH, Karslioglu Y, Deveci MS, Durmaz A. Relationship between postoperative recurrence rate and eosinophil density of nasal polyps. Ann Otol Rhinol Laryngol. 2010;119(7):455-9. doi: 10.1177/000348941011900705. [PubMed: 20734966].

18. Videler WJ, Van Hee K, Reinartz SM, Georgalas C, Van der Meulen FW, Fokkens WJ. Longterm low-dose antibiotics in recalcitrant chronic rhinosinusitis: a retrospective analysis. Rhinology. 2012;50(1):45-55. doi: 10.4193/Rhino11.123. [PubMed: 22469605].

19. Dalziel K, Stein K, Round A, Garside R, Royle P. Endoscopic sinus surgery for the excision of nasal polyps: a systematic review of safety and effectiveness. Am I Rhinol. 2006;20(5):506-19. doi: 10.2500/ajr.2006.20.2923. [PubMed: 17063747]

20. Gevaert P, Bachert C, Holtappels G, Perez Novo C, Van der Heyden J, Fransen L, et al. Enhanced soluble interleukin 5 receptor alpha expression in nasal polyposis. Allergy. 2003;58(5):371-9. doi: 10.1034/j.1398-9995.2003.00110.x. [PubMed: 12752323].

21. Simon HU, Yousefi S, Schranz C, Schapowal A, Bachert C, Blaser K. Direct demonstration of delayed eosinophil apoptosis as a mechanism causing tissue eosinophilia. J Immunol.
1997;158(8):3902-8. [PubMed: 9103460].

21. Akhtar S, Ikram M, Azam I, Dahri T. Factors associated with recurrent nasal polyps: a tertiary care experience. J Pak Med Assoc.2010;60(2):102-4. [PubMed: 20209694].

22. Tecimer SH, Kasapoglu F, Demir UL, Ozmen OA, Coskun H Correlation between clinical findings and eosinophil/ neutrophil ratio in patients with nasal polyps. European Archives of Oto-Rhino-Laryngology.2015;272(4):915-21. doi: 10.1007/s00405-014-3174-4. [PubMed: 25007735]

23. Balouchi M, Berjis $N$, Okhovvat A, Abbasi $H$, Talebi $S$ Pathologic findings in sinonasal polyposis and predisposing factors. J Isfahan Med Sch. 2007;24(83):44-8.

24. Cohen, J. Statistical Power Analysis of the Behavioral sciences. 2nd Ed. New York: Academic Press; 1988.

25. Bezerra TF, Piccirillo JF, Fornazieri MA, Pilan RR, Pinna FD, Padua FG, et al. Assessment of quality of life after endoscopic sinus surgery for chronic rhinosinusitis. Braz J Otorhinolaryngol. 2012;78(2):96-102. [PubMed: 22499376]

26. Moghadasi H, Sanei Taheri M, Jalali AH, Shakiba M. Correlation of Lund-Mackay and SNOT-20 before and after fanctional endoscopic Sinus Surgery (FESS): Does the baseline data predict the response rate? Iran J Radiol. 2009;6(4):207-14.

27. Piccirillo JF, Merritt Jr MG, Richards ML. Psychometric and clinimetric validity of the 20-Item Sino-Nasal Outcome Test (SNOT20). Otolaryngol Head Neck Surg. 2002;126(1):41-7. doi: 10.1067/mhn.2002.121022. [PubMed: 11821764].

28. Pynnonen MA, Kim HM, Terrell JE. Validation of the sino-nasal outcome test 20 (SNOT-20) domains in nonsurgical patients. Am J Rhinol Allergy. 2009;23(1):40-5. doi: 10.2500/ajra. 2009.23.3259. [PubMed: 19379611].

29. Hopkins C, Browne JP, Slack R, Lund V, Brown P. The LundMackay staging system for chronic rhinosinusitis: How is it used and what does it predict? Otolaryngology Head Neck Surg. 2007;137(4):555-61. doi: 10.1016/j.otohns.2007.02.004. [PubMed: 17903570].

30. Naghdi S, Anjeie F, Nakhostin Ansari N, Fathali M. Development, cultural adaptation, reliability and validity of Persian version of sino-nasal outcome test in chronic rhinosinusitis: a brief report. Tehran Univ Med J. 2013; 70(11):735-740.

31. Rosai J. Rosai and Ackerman's, Surgical Pathology. 10th Edition. Elsevier;2011. P: 292.

32. Hoseinalipoor Z, Yarmohammadi M, Jalali Nadooshan M Yaraee R. Pathologic and clinical findings in sinonasal polyposis patients with or without nasal septal deviation. J Adv Med Biomed Res. 2014;22(91):109-20.

33. keda K, Shiozawa A, Ono N, Kusunoki T, Hirotsu M, Homma H et al. Subclassification of chronic rhinosinusitis with nasal polyp basedon eosinophil and neutrophil. Laryngoscope. 2013;123(11):E1-9. doi: 10.1002/lary.24154. [PubMed: 23670893].

34. Chaaban MR, Walsh EM, Woodw orth BA. Epidemiology and differential diagnosis of nasal polyps. Am J Rhinol Allergy. 2013;27(6): 473-478. doi: 10.2500/ajra.2013.27.3981. [PubMed: 24274222].

35. Hoseinalipoor Z, Yarmohammadi M, Jalali Nadooshan M, Yaraee R. Pathologic and clinical findings in sinonasal polyposis patients with or without nasal septal deviation. J Adv Med Biomed Res. 2014;22(91):109-20.

36. Gevaert P, Van Bruaene N, Cattaert T, Van Steen K, Van Zele T, Acke $\mathrm{F}$, et al. Mepolizumab, a humanized anti-IL-5 mAb, as a treatment option for severe nasal polyposis. J Allergy Clin Immunol. 2011;128(5):989-95.e1-8. doi: 10.1016/j.jaci.2011. 07.056. [PubMed: 21958585].

37. Bassiouni A, Wormald PJ. Role of frontal sinus surgery in nasal polyp recurrence. Laryngoscope. 123(1):36-41. doi: 10.1002/ lary.23610. [PubMed: 23070897].

38. Matsuwaki Y, Ookushi T, Asaka D, Mori E, Nakajima T, Yoshida $\mathrm{T}$, et al. Chronic rhinosinusitis: risk factors for the recurrence of chronic rhinosinusitis based on 5-year follow-up after endoscopic sinus surgery. Int Arch Allergy Immunol. 2008; 146(suppl. 1):77-81. doi: 10.1159/000126066. 